\title{
ENCONTROS ESTÉTICOS/POÉTICOS ENTRE MÚSICA E BEBÊS NA CRECHE
}

\author{
Sandra Richter ${ }^{1}$ \\ Clarice de Campos Bourscheid ${ }^{2}$
}

\section{Resumo}

O ensaio aborda a intimidade entre as dimensões estética e poética da linguagem no contexto da creche para propor uma escuta fenomenológica dos encontros entre adultos e bebês com a experiência da música como ação lúdica do corpo expressivo no mundo. Ao considerar que sem estética a vida carece de sabor assim como sem poética carece de sentido, parte da compreensão merleaupontiana do corpo sensível como fonte primeira de significação para afirmar a inseparabilidade entre sensível e inteligível na ação de aprender a co-existir. A intenção educacional é reivindicar outra racionalidade para resistir à tendência simplificadora nos encontros entre adultos e bebês com a pluralidade nos modos de interagir em linguagem. Para tanto, pensa o acontecimento estético e poético - no sentido dos termos aisthesis e poiésis - do vínculo da sonoridade e do silêncio com a vida tomando como ponto de partida reflexivo não o que o bebê faz e sim como vivencia o que faz nos encontros musicais na creche. O estudo permite afirmar a potência vital e lúdica do corpo expressivo sentir a si próprio e ao mundo na pluralidade dos modos de estar em linguagem que dinamizam a vida cotidiana do agir, produzir, criar, fazer.

Palavras-chave: Educação de Bebês; Linguagem; Música; Estética; Poética

\section{PENSAR E SONHAR OUTRA RACIONALIDADE NA EDUCAÇÃO DE BEBÊS}

\footnotetext{
${ }^{1}$ Doutora em Educação pela Universidade Federal do Rio Grande do Sul, professora adjunta do Departamento de Educação da Universidade de Santa Cruz do Sul, líder do grupo de pesquisa Linguagens, Cultura e Educação - LinCE/UNISC-CNPq. Rua Thomaz Flores, 1164. Santa Cruz do Sul. Brasil. 51 99564191. Email: srichter@unisc.br

${ }^{2}$ Mestre em Educação pela Universidade de Santa Cruz do Sul, professora de música na Educação Infantil. Rua Dona Leonor 194/1504 Porto Alegre. Brasil. 5193618748. E-mail: claricebourscheid@gmail.com
} 
Uma criança pode crescer como um poema que se canta. Também ela pode cantar um poema enquanto cresce. (FERRÃO, A. M.; RODRIGUES, P. F. Sementes de música para bebés e crianças)

O desafio acadêmico de propor uma reflexão em torno da presença da música no âmbito educacional da creche está em apresentar ao leitor, uma experiência difícil de ser fragmentada na sua complexidade de acontecimento simultaneamente sensível e intelectual, tanto para o adulto quanto para o bebê e a criança pequena. Como neles separar a totalidade da ação vital de um corpo em movimento de ver, escutar, tocar, degustar, soar, cheirar, pensar? Mais, como decompor analiticamente essa "energia vital desprendida pelo vapor de um corpo vivo que é, que deseja, que intui, que sente, que recorda, que pressente, que pensa, que quer, que sonha, que imagina, que pode, que faz" (DERDYK, 2001, p. 17), desde o nascimento?

Talvez sonhar com uma educação que considere a complexidade das dimensões estésica $^{3}$ e poética ${ }^{4}$, através da ludicidade do corpo linguageiro que sente e transforma o mundo, possa contribuir para pensar uma educação sensível aos desafios que os bebês e as crianças pequenas colocam aos adultos na contemporaneidade. Assim, para enfrentar a complexidade do desafio educacional de considerar a "energia vital" do corpo em interação com o mundo, este ensaio persegue argumentos que permitam afirmar a inseparabilidade entre sentir e o vigor do agir - entre estética e poética - no contexto de vida coletiva da creche. Tomamos como ponto de referência uma escuta fenomenológica dos encontros dos bebês com a música ${ }^{5}$ a partir da compreensão do termo estética "como forma de vida, de empatia física e emocional com o entorno físico e social, que vai criando uma história pessoal de cada criança tecida com o entorno, com a cultura" (ESLAVA, 2007, p. 42) e o termo poético como abertura à ação linguageira que anima as coisas para nos situar entre elas (RICHTER, 2011).

É porque as diferentes formas de estar em linguagem constituem o humano e seu modo de conviver que todas as crianças "têm que aprender a falar, a cantar, a desenhar, a

\footnotetext{
${ }^{3}$ Cf. Dicionário Houaiss da Língua Portuguesa, o termo estesia significa sensibilidade ou capacidade de perceber sensações e/ou o sentimento da beleza enquanto o termo estética significa refletir filosoficamente sobre a beleza sensível e o fenômeno artístico.

${ }^{4}$ Com Paul Ricoeur (2002) estendemos o termo poético para além da poesia até o sentido de produção de sentido, de energia criadora de inovação. Para Meschonnic (2001, p. 292), o poético emerge cada vez que "uma forma de vida transforma uma forma de linguagem e se reciprocamente uma forma de linguagem transforma uma forma de vida".

5 Pesquisa vinculada ao grupo Linguagens, Cultura e Educação - LinCE/UNISC e realizada por Bourscheid (2014) entre 2012 e 2013 com um grupo de 14 crianças entre um e dois anos de idade de uma creche do sistema privado de ensino do município de Porto Alegre-RS.
} 
modelar, a dramatizar, a dançar, ou seja, têm que aprender a narrar o vivido e o que pode ser vivido para situar-se na convivência coletiva” (RICHTER; BARBOSA, 2010, p. 92). Esse é o radical desafio de coexistir na creche, pois exige compreender o projeto educativo com bebês e crianças pequenas em sua abertura sensível à surpresa e ao imprevisto da experiência linguageira de vivermos juntos - bebês, crianças pequenas e adultos professores - e não como um plano previamente determinado para viver. Considerar a abertura à imprevisibilidade na convivência com bebês e crianças pequenas exige afirmá-los em sua potência de ação autônoma $^{6}$ e interação no e com o mundo, capazes de auto-organizarem-se e de coorganizarem-se nas suas interações com e no mundo. Assim, pensamos na responsabilidade da docência com bebês como compromisso ético com uma racionalidade mais amorosa, mais lenta, mais cuidadosa com os começos linguageiros do humano, com os processos inventivos de iniciar-se na convivência.

Nessa expectativa, o que apresentamos é uma possibilidade de pensar como encontros entre adultos e bebês podem contribuir para realizar uma educação na qual a ação de aprender acontece no entrelaçamento entre o intelectual e o sensível, pois são inseparáveis não apenas nos processos de aprendizagem, mas, sobretudo, no contexto cotidiano da experiência do movimento do corpo no mundo ${ }^{7}$. A admiração pelas forças da arte na educação - a qual vem promovendo a aproximação de nossas trajetórias de professoras e pesquisadoras - nos faz pensar e sonhar ações educativas como encontros estéticos e poéticos que podem ser favorecidos desde a convivência entre adultos e bebês na creche e que a intencionalidade de promovê-los seja compromisso também do professor de música.

Nesse sentido, buscamos ampliar as interrogações ao nos determos tanto na escuta aos bebês quando adultos favorecem espaços, tempos e materialidades para a exploração estética de sonoridades quanto na escuta ao que essas "ofertas" produzem como expressão do corpo provocado a interagir e significar essa experiência com as sonoridades. Trata-se de pensarmos que, para um bebê, não há sentido em fragmentar possibilidades de ação e interação no mundo

\footnotetext{
${ }^{6}$ Ação autônoma para Tardos e Szanto (2004), é traduzida como aquela escolhida e realizada pela criança enquanto capacidade de movimentar-se, disposição para iniciativas nas suas relações com outros, interesse pelo mundo e prazer lúdico de surpreender-se com a imprevisibilidade dos acontecimentos gerados pelo movimento, portanto, enquanto uma necessidade fundamental do humano desde seu nascimento.

${ }^{7}$ Para Merleau-Ponty (2011, p. 253), "é por meu corpo que compreendo o outro, assim como é pelo meu corpo que percebo "coisas"”. Nesse sentido, para o filósofo, "a percepção do mundo é apenas uma dilatação de meu campo de presença, ela não transcende suas estruturas essenciais, aqui o corpo permanece sempre agente e nunca se torna objeto". (MERLEAU-PONTY, 2011, p. 408).
} 
a partir da histórica cisão ocidental entre saber sensível (corpo) e conhecimento intelectivo (mente).

Para não fragmentar a linguagem em linguagens estanques, pois nossa formação aponta para a complexidade da confluência sensível - estética e poética - de um corpo capaz de produzir sentidos cantando, desenhando, pintando, falando, modelando, dançando, utilizamos o termo saber sensível em vez de conhecimento sensível. Para Duarte Jr. (2001, p. 14), a concepção do verbo saber possui uma denotação mais ampla ao evidenciar a articulação com o viver cotidiano de seu detentor, "incorporadas" a ele. E é bem este o termo, na medida em que incorporar significa precisamente trazer ao corpo, fundir-se nele: o saber constitui parte integrante do corpo de quem o possui, torna-se uma qualidade sua. Assim, o autor resgata a acepção mais antiga do verbo saber como "ter o sabor de" para afirmar que "o saber carrega um sabor, fala aos sentidos, agrada ao corpo, integrando-se, feito um alimento, à nossa existência" (DUARTE Jr., 2001, p. 14). Aqui, os saberes sensíveis e os conhecimentos intelectivos ou conceituais se complementam, pois "tudo aquilo que é sentido por nós faz sentido, ao mesmo tempo que nos indica um sentido a seguir" (DUARTE Jr., 2001, p. 217). Por isso, Le Breton (2009, p. 42) pode afirmar que "o corpo não é o primo pobre da língua, mas seu parceiro homogêneo na permanente circulação de sentido, a qual consiste na própria razão de ser do vínculo social". Nenhuma palavra existe independentemente da ação do corpo que a implica e lhe confere sentido na convivência.

Nessa compreensão, buscamos ultrapassar os limites de uma abordagem expressa exclusivamente nos termos pedagógicos de ensinar crianças para nos determos também na imprevisibilidade nos modos singulares do corpo aprender a interagir no coletivo. Para tanto, concebemos com Duarte Jr. (2001, p. 11-12) o verbo sentir e seu particípio passado - sentido ${ }^{8}$ - como "tudo aquilo que é imediatamente acessível a nós através dos órgãos dos sentidos, tudo aquilo captado de maneira sensível pelo corpo, já carrega em si uma organização, um significado, um sentido". Torna-se então importante compreender o verbo agir no sentido que lhe dá Arendt (2004, p.191) ao afirmar que "o fato de que o homem é capaz de agir significa que se pode esperar dele o inesperado, que ele é capaz de realizar o infinitamente improvável". Por esse poder radical de surpresa e inovação, o humano é insubstituível e

\footnotetext{
${ }^{8}$ Duarte Jr. (2001, p. 12) destaca que a palavra sentido possui dezoito significações em nossa língua além daquelas advindas de expressões compostas. Porém, podemos constatar "um bom número de referências à capacidade humana de apreender a realidade de modo consciente, sensível, organizado e direcionado (ou intencionado, como diriam os fenomenólogos). Em que pese a duplicidade de termos, convém mesmo notar que em nossa vida existe primordialmente um sentido no sentido".
} 
único, pois cada criança que nasce traz consigo essa avassaladora força do imprevisto e do imprevisível. Aqui, a ação de aprender aponta para o processo de atualização de virtualidades do corpo desafiado pelo mundo e pelas coisas que exigem nossas forças, tornando as noções de provocação e de conquista indispensáveis para compreender o movimento intensivo de um corpo aprendendo a estar em linguagem. Desde o nascimento.

Para afirmarmos a relevância educacional dos adultos organizarem e oferecerem experiências linguageiras de cantar, dançar, soar, pintar, desenhar, dramatizar, modelar, vocalizar poesia, enfim de intencionalmente garantirem no tempo e espaço da creche a multiplicidade expressiva do corpo estar em linguagem, propomos uma abordagem fenomenológica do vivido com bebês e crianças pequenas nos seus encontros lúdicos com a música, sonoridades, ritmos, instrumentos musicais, objetos sonoros e silêncio.

A fenomenologia do corpo sensível em Maurice Merleau-Ponty (2011) ${ }^{9}$ contribui de modo especial para pensarmos a experiência musical já que essa, "antes de um saber, é uma vivência, que é o tema por excelência da fenomenologia" (HELLER, 2006, p. 13). A relevância da abordagem merleaupontiana do corpo sensível ${ }^{10}$ para pensar o acontecimento estético e poético do vínculo da sonoridade e do silêncio com a vida, tomando como ponto de partida reflexivo, os encontros musicais vividos na creche, está em reivindicar outra racionalidade capaz de resistir à tendência de simplificação nos encontros entre adultos e bebês com a pluralidade nos modos de estar e interagir em linguagem. Como diz o poeta,

\begin{abstract}
Não há cores nem sons em si, desprovidos de significação: tocados pela mão do homem, mudam de natureza e adentram o mundo das obras. E todas as obras desembocam no significado; o que o homem toca se tinge de intencionalidade: é um ir para... O mundo do homem é o mundo do sentido. Ele tolera a ambiguidade, a contradição, a loucura ou o embuste, não a carência de sentido. O próprio silêncio é povoado de signos. (...) As diferenças entre o idioma falado ou escrito e os outros plásticos ou musicais - são muito profundas; mas não a ponto de fazer-nos esquecer que todos são, essencialmente, linguagem: sistemas expressivos dotados de poder significativo e comunicativo. (PAZ, 2012, p.27-28).
\end{abstract}

\footnotetext{
${ }^{9}$ Para Heller (2006, p. 12), "há tantas fenomenologias quanto fenomenólogos. Mais importante que optar por uma 'corrente' fenomenológica, seja essa corrente husserliana, heideggeriana, merleau-pontyana ou outra, é compreender a fenomenologia como movimento histórico". Nas palavras de Chaú́ (2002, p. VI), "a interrogação de Merleau-Ponty se debruça sobre o que designa como 'tradição cartesiana', isto é, o dualismo corpoconsciência, fato-ideia, sujeito-objeto, que marcou o pensamento ocidental com as filosofias da consciência e o objetivismo científico".

10 "Contra a herança intelectualista, Merleau-Ponty afirma a encarnação da consciência num corpo cognoscente e reflexivo, dotado de interioridade e de sentido, relacionando-se com as coisas como corpos sensíveis, também dotados de interioridade e de sentido. Nossa relação fundamental com o mundo é a da intercorporeidade, fundadora da intersubjetividade e fundada por ela numa troca e num cruzamento intermináveis: os outros não são coisas nem partes da paisagem, são nossos semelhantes". (CHAUÍ, 2002, p. 274).
} 
A intenção educacional de problematizar as concepções de linguagem que sustentam projetos pedagógicos na creche está em refletir nosso papel de adultos educadores, quem são, para nós, os bebês e as crianças pequenas, e qual contexto de vida sonhamos compartilhar com eles. A partir de nossas pesquisas no âmbito da educação da infância, nos interessa estudar e discutir a complexidade dos encontros linguageiros entre adultos e bebês, entre bebês e bebês e entre adultos e adultos no contexto de vida coletiva da creche para nos aproximarmos de um campo maior - a educação do sensível. Nossa expectativa é contribuir com argumentos que reivindiquem, desde os primeiros anos de vida, a relevância de uma educação que considere a inseparabilidade entre as dimensões sensível e inteligível na ação de aprender a co-existir. As experiências estética e poética, em sua pluralidade de manifestações, ao contribuírem para uma formação que considera a complexidade do humano em seus diferentes tempos e ritmos, nega a simplificação do encontro entre arte, educação e infância. Porém, como afirma Richter (2009, p. 58), uma nebulosidade teórica-metodológica envolve as questões relacionadas ao estético e ao poético que exigem outras reflexões.

\section{ESTÉTICA/POÉTICA COMO EXPERIÊNCIA DE LINGUAGEM}

Os termos estética e poética convocam campos historicamente marcados por profundos e extensos significados que tensionam debates e opções educacionais. Buscamos aqui abordá-los a partir de noções mais próximas do sentido originário de ambas: aisthesis e poiésis. Em suas raízes gregas, a primeira indica a estesia como "primordial capacidade do ser humano de sentir a si próprio e ao mundo num todo integrado" (DUARTE JR., 2001, p. 13); e a segunda, ao indicar a pluralidade de acepções que dinamizam o estar no mundo, isso é, a vida cotidiana do agir, produzir, criar (RICHTER, 2011), "aponta para uma direção que se aproxima da origem da própria palavra fazer ${ }^{11}$ : um fazer em comunhão com uma especificidade espiralada onde o corpo espelha e reflete outras modalidades para o fazer" (DERDYK, 2001, p. 26).

Implica compreender com Merleau-Ponty (2011) que, enquanto faço (pinto, canto, toco, falo, danço), sei de mim, esquecido de mim. “A maravilha da linguagem é que ela se faz

\footnotetext{
11 “O fazer, o poïen, do qual desejo me ocupar, é aquele que termina em alguma obra e que eu acabarei restringindo, em breve, a esse gênero de obras que se convencionou chamar de obras do espírito. São aquelas que o espírito quer fazer para seu próprio uso, empregando para esse fim todos os meios físicos que possam lhe servir”. (VALÈRY, 1999, p. 180-181).
} 
esquecer: sigo com os olhos as linhas no papel e, a partir do momento em que sou tomado por aquilo que elas significam, não as vejo mais” (MERLEAU-PONTY, 2011, p. 537). A expressão se dilui no expresso porque, na concepção fenomenológica de Merleau-Ponty (2011), minha percepção não depende de mim: ela se faz em mim, por mim, comigo, pois não há um eu anterior à resposta - um eu à espera de um estímulo para uma resposta - nem durante, nem depois. Aqui, eu e minha percepção somos simultâneos. Quanto ao sentir, à estesia, "o sujeito da sensação não é nem um pensador que nota uma qualidade, nem um meio inerte que seria afetado ou modificado por ela; é uma potência que co-nasce em um certo meio de existência ou se sincroniza com ele" (MERLEAU-PONTY, 2011, p. 285). Torna-se então importante compartilhar com Duarte Jr. (2001, p. 155) o pensamento de James Hillman $^{12}$ ao afirmar que

aisthesis é como conhecemos o mundo. [...] Assim, o que quero dizer por reação estética aproxima-se mais de um sentido animal da palavra - um faro para a inteligibilidade aparente das coisas, seu som, cheiro, forma, falar para e através das reações de nosso coração, respondendo a olhares e linguagem, tons e gestos das coisas entre as quais nos movemos. (HILLMAN apud DUARTE JR., 2001, p. 155).

O saber sensível, por suas raízes corporais é anterior às práticas e simbolizações artísticas ao implicar a anterioridade do encontro vital do corpo com cores, sabores, texturas, odores, formas, sonoridades, silêncios, que nos colocam no mundo e são por nós incorporados como significados. O sentir é esse elo de interação e comunicação vital com o mundo que o torna familiar em nossa vida. Antes de nomear e conhecer o mundo, o corpo já firmou com ele um pacto: meu corpo "sabe" (“eu posso") melhor que "eu” (“eu penso") o que significam quente, frio, leve, saboroso, agudo, oloroso, pesado, mole, e, por isso, o sensível não é por ele definido nem como efeito de um estímulo “exterior” (MERLEAU-PONTY, 2011, p. 29), nem como associação ou recordação (MERLEAU-PONTY, 2011, p. 47).

Aqui o prazer estésico - sensual e afetivo - que emerge de todas as maravilhas que o mundo permite saborear e do prazer de sentir de outros modos o vivido, torna-se prazer intelectual. Para Vecchi (2006, p. 20), a experiência estética, sendo inseparável da experiência humana, "ocupa com facilidade diversos campos e é transversal a várias disciplinas", convertendo-se em "modalidade de busca, chave de interpretação e lugar de experiência". De outro modo, Cabanellas, Eslava e Polonio (2007, p. 60) reafirmam o mesmo ao escreverem

\footnotetext{
${ }^{12}$ In: HILLMAN, James. Cidade \& alma. São Paulo: Studio Nobel, 1993. p. 20-21.
} 
que "existe em toda cultura uma atitude fundamental ante a vida que, antes de expressar-se em ações religiosas, estéticas, ou filosóficas, se manifesta como ritmo". Torna-se então relevante compartilhar com o músico e pesquisador Heller (2007) a concepção de ritmo como temporalidade do corpo.

Podemos dizer que o ritmo é uma compreensão temporal e motriz que se dá com/em meu corpo, anterior a qualquer outro tipo de compreensão. Na noção de ritmo está implícito não um corpo-objeto comandado por um sujeito, mas um corpo expressivo - o corpo-vivido ou corpo-próprio, descrito pela fenomenologia. (HELLER, 2007, p. 71).

Para o autor, o ritmo emerge da relação indissociável entre tempo, movimento e expressão, como compreensão do tempo encarnada, isto é, como compreensão primal do tempo exercida com o corpo, anterior à experiência de pensamento. Para Heller (2006, p. 123), se som e gesto estão envolvidos num mesmo todo, sendo o fenômeno expressivo justamente esse todo, não há necessidade de comandar, ou "estimular" o corpo para que ele se expresse, pois "expresso-me, e isso é ritmo. Não ajo: deixo que a ação se faça; deixo que a expressão apareça. $\mathrm{Na}$ espacialidade do gesto o tempo se dilata e se contrai, dilatando-se e contraindo-se simultaneamente meu corpo".

Esse é um grande desafio para compreender os bebês e as crianças pequenas em seus detalhes e especificidades de começar ações no mundo, pois significa considerar, no cotidiano da creche, suas necessidades tanto de atenção e cuidado quanto de provocações e desafios que considerem as potencialidades de seu corpo em movimento no mundo. Para Merleau-Ponty (2011, p. 192), a motricidade não é serva do pensamento, mas "intencionalidade original", pois “originariamente a consciência é não um 'eu penso que', mas um 'eu posso"”.

Um movimento é aprendido quando o corpo o compreendeu, quer dizer, quando ele o incorporou ao seu 'mundo', e mover seu corpo é visar as coisas através dele, é deixá-lo corresponder à sua solicitação, que se exerce sobre ele sem nenhuma representação. [...] Portanto, não se deve dizer que nosso corpo está no espaço nem tampouco no tempo. Ele habita o espaço e o tempo. (MERLEAU-PONTY, 2011, p. $193)$.

A compreensão fenomenológica do corpo habitar o espaço e o tempo permite que Heller (2006; 2007) conteste o modo generalizado de conceber a música como "arte temporal” porque ocorre no tempo, para afirmar que "ela não ocorre 'no tempo': ela é tempo, ela cria tempo" (HELLER, 2007, p. 73). Do mesmo modo, se não estamos no espaço: somos espaço, e "é nessa espacialidade primordial que reconhecemos o corpo enquanto 
essencialmente motriz" (HELLER, 2007, p. 61), podemos pensar a expressão musical do corpo e não "através do corpo". Mais, se esse movimento expressivo organiza ele mesmo o corpo numa auto-organização, podemos pensar a relevância educacional da interação entre bebês e música, pois "ao expressar-se, o corpo move a si próprio. Esse é o fundamento da motricidade. O corpo não se move para expressar-se: ele se expressa movendo-se" (HELLER, 2006, p. 63). No pensamento merleaupontiano, "esse corpo não é um movido, mas um movente" já que nos encontramos diante de uma motricidade que independe de decisões previamente deliberadas por mim, pois "há um esquema corporal através do qual me movo integrado ao espaço (uma motricidade de situação, não de posição), meu corpo em relação de mútua fundação com os outros corpos e com tudo que o rodeia” (HELLER, 2007, p. 70).

Por isso, a criança em ação lúdica não busca: encontra. Nesse sentido, para Heller (2006, p. 116), “o fazer da criança (expresso em seu jogo) constitui-se numa prática criadora, num fazer poético". Convém destacar com Derdyk (2001, p. 24), que a compreensão do ato criador como operação poética

\begin{abstract}
territorializa um campo específico de atuação: não é qualquer fazer um ato criador aquele que provoca um estado poético impregnado de uma consciência ou percepção inusual -, não é simplesmente um constante fazer que garante a revelação de uma outra ordem de grandeza dos sentidos. Numa direção inversa às enunciações que dão forma à linguagem pragmática e funcional - necessária para nossa sobrevivência cotidiana e comunicação imediata - , o ato criador instaura uma maneira única (pessoal, individual e subjetiva) e, simultaneamente, coletiva de ingressar em um tempo e um espaço ainda fora de forma. Protagonista de uma trama que existe porque existe um corpo presente e atuante, o ato criador faz de si mesmo um outro fazer, fazendo do fazer um outro ser. (DERDYK, 2001, p. 24).
\end{abstract}

É o que Lino (2008) defende, em seu estudo da relação entre música, educação e infância, ao propor o ato de barulhar ${ }^{13}$ como brincadeiras das crianças com as ações de sentido provocadas pela escuta. Em sua perspectiva, o verbo "barulhar" designa "a sensibilidade ao impossível, esse outro do nosso saber, de nosso dominar ou produzir" (LINO, 2008, p. 355). Para Lino (2008, p. 360), o movimento do corpo lúdico e o fazer poético do barulhar das crianças, seus fazeres nos espaços de compor-improvisar, configuram uma "necessidade transbordante. Sem pedir licença, compunham-improvisavam porque

\footnotetext{
${ }^{13}$ Para Lino (2010, p. 84-85), o "barulhar" é "este ato de fazer barulho, de sonorizar sem prévia sistematicidade e determinação" para expressar "uma sensibilidade que em sua dimensão primeira é a de um corpo em contato com o real. Corpo que estabelece uma relação de presença e doação ao se movimentar, se fazer ressoar num tempo e num espaço, emergindo o sensível como característica da infância. Sensibilidade que, sendo social e histórica é condição de pôr-se no mundo soando".
} 
precisavam”. Precisavam fazer. Brincar é fazer e fazer é pensar, é enfrentar o instante da escolha e da decisão, é iniciar uma ação no mundo, tomar a iniciativa de começar algo (ARENDT, 2004), de acolher ou recusar o acaso que engendra processos transformadores de investigação e experimentação linguageira.

Talvez, se compartilhamos com Derdyk (2001, p. 25) a compreensão de experiência poética como possibilidade linguageira de "fabricar, emprestar, construir, negar, afirmar, extrair, atribuir, relacionar, imanta o mundo de sentidos para serem sentidos", configurando distintas maneiras de interagir com a multiplicidade do mundo, possamos acolher com Lino (2008, p. 362) que as crianças precisavam fazer um outro ser, "lançar o corpo no movimento do sensível" e mostrarem que sabem estar em linguagem, pois "sabem escutar, sabem compor, sabem improvisar, sabem interpretar, sabem as músicas que afrontam o poder adulto, sabem onde e quando podem barulhar". Nesse ato de "barulhar" na infância, "a música instala-se no corpo" - para brincar - e "ensina o ouvido a pensar, fazendo com que a criança possa entender o que ainda não compreende" (LINO, 2008, p. 363). Nesse movimento, são desafiadas a aprenderem a instaurar sentidos que dão sentido ao estar junto no mundo. Um modo de aprender próprio das crianças,

\footnotetext{
direto, fantástico, investigativo, transbordante, fabulador, porque admirado diante das múltiplas situações de perplexidade e estranhamento a enfrentar. Um encantamento que força o corpo a mexer-se para aprender fazeres compartilhados que enfrentem as contradições e as ambiguidades de participar do coletivo desde a infância. A negligência com o corpo brincante nos processos de aprendizagem das crianças subestima as experiências que emergem de um pensamento em ato, aquele que decide fazer algo. (RICHTER; FRONCKOWIAK, 2011, p. 41).
}

Tal afirmação implica compreender que o bebê é simultaneamente dependente dos cuidados do adulto e potente em sua capacidade de tomar a iniciativa de agir e interagir com o mundo e os outros desde que nasce. Essa ambivalência do humano, desde bebê, é destacada por Eslava (2007, p. 51) ao reivindicar que os bebês e as crianças sejam compreendidos pelos adultos "na descontinuidade de sua aprendizagem desde o sentido que têm seus silêncios, suas pausas, suas repetições e mudanças emocionais". Para tanto, torna-se importante não apenas considerar e aceitar, mas fundamentalmente confiar nas crianças e acolher seus tempos de tentar, de explorar, de experimentar, de aprender, de reconhecer, de inventar. Porém, antes, implica compreender com Merleau-Ponty (2011, p. 537) que "a linguagem adquire sentido para a criança quando constitui situação para ela”. E as situações linguageiras são sempre híbridas, nunca puras em sua imprevisibilidade de abertura aos outros e ao mundo. 
Para o filósofo, o pensamento ${ }^{14}$ e a expressão se constituem simultaneamente, não sendo a expressão e a linguagem instrumentos ou invólucros do pensamento, mas presença do corpo no mundo, pois é o corpo que mostra, ele que fala, ele que canta e que se movimenta, e que para poder exprimir, precisa tornar-se pensamento ou então a intenção que ele nos significa. Supõe considerar que se a experiência da linguagem, na fenomenologia merleaupontiana, é relação consigo, com outrem, com o mundo estético e com o mundo cultural, a experiência do pensamento se enraíza no corpo, se efetua no modo da experiência (CHAUÍ, 2002). Cabe aqui recuperar, com Lazzarin (2013), o sentido formativo do termo “experiência" para destacar sua etimologia latina

\begin{abstract}
ligada ao radical Peri, que significa "obstáculo" ou "dificuldade". O mesmo radical compõe a palavra periculum (perigo) e o verbo aperire (abrir). Assim, experiência sugere um "abrir-se para o perigo" ou o "aprendizado que resulta do enfrentamento de dificuldades e perigos", ligado à constatação dos próprios limites humanos. (LAZZARIN, 2013, p. 408).
\end{abstract}

Nesse sentido formativo, a experiência diz respeito ao encontro de quem experiência algo consigo mesmo, à inversão de voltar-se sobre si mesma, e não a um somatório de vivências (LAZZARIN, 2013, p. 409). Essa concepção de experiência como aprendizagem promovida pelo enfrentamento de nossos próprios posicionamentos, e não como experimento ou acúmulo de vivências estanques, promove a abertura à ação ou interação transformativa do encontro entre adultos e bebês ou crianças pequenas em seu poder de subverter padrões e questionar a definição tradicional de "experiência musical" como objetividade da "arte dos sons". Para Heller (2006),

quando se fala em "objeto musical" parece haver algo como "o objeto" da música, objeto então relacionado à materialidade da música - aos sons? (curiosamente, a ninguém ocorreria responder que o objeto da Literatura consiste nas letras do alfabeto). Se a essência da música se limitasse ao som, nosso estudo se restringiria à acústica. Se a essência musical estivesse na ação do som sobre um sujeito, nosso estudo se restringiria à psicologia ou à psicoacústica. $\mathrm{O}$ fenômeno musical é, em seu todo, bem mais complexo [...]. (HELLER, 2006, p. 17).

O fenômeno musical é bem mais complexo porque diz respeito ao vínculo da sonoridade com a vida ao apontar, nas palavras de Heller (2006, p. 19), “para o nãoverbalizável, para o invisível, para o silêncio. Há um corpo musical - o som - que é, porém,

\footnotetext{
${ }^{14}$ Segundo Chauí (2002, p. 274), para Merleau-Ponty “o pensamento começa e se faz nas relações de nossa vida encarnada com o mundo: a percepção e a linguagem".
} 
simultaneamente ausência, campo que articula em torno de si o infinito de possibilidades". Na perspectiva merleaupontina de Heller (2006, p. 20), "se a linguagem nos conduz às coisas mesmas, é porque, antes de ter um significado, ela é significação”. Por isso, para o autor, o movimento que "assegura a vivência e a espontaneidade do fazer musical" reside na expressividade do gesto, "na abertura entre as notas, no vazio criativo, no movimento" (HELLER, 2006, p. 22). Música, nesse sentido, mais do que a objetividade de uma ação, é um modo de ação no mundo.

Modo de ação que, por ser movimento do corpo no mundo, implica para MerleauPonty (2011, p. 229) "uma operação primordial de significação em que o expresso não existe separado da expressão" e, portanto, "a expressão é a linguagem da coisa mesma e nasce de sua configuração" (MERLEAU-PONTY, 2011, p. 432). Heller (2006, p. 56), ao interrogar o sentido de "nos deixarmos levar pela música", explicita que, criado o fluxo expressivo, "não há mais necessidade de comandar os movimentos. A expressão organiza ela mesma o corpo". Desse modo, o pensamento de Merleau-Ponty contribui para a ultrapassagem da polarização entre expressão e corpo (é muito diferente dizer que "me expresso através do corpo" de dizer “meu corpo se expressa”) já que sua concepção de expressão não diz respeito "à veiculação de um determinado conteúdo semântico. Não falaremos em expressar algo 'através' de um gesto; no gesto expressivo encontramos uma totalidade indivisível entre música e corpo" (HELLER, 2006, p. 57).

A música, como um modo de ação do corpo expressivo no mundo, "emerge na infância como brincadeira, acolhendo e se nutrindo de vários repertórios que lhe conferem identidade, servem à diversão e à alegria para expressar a necessidade de lançar o corpo à sensibilidade de soar" (LINO, 2010, p. 84). Se consideramos com Maturana (1999b, p. 60) que "aprender tem a ver com as mudanças estruturais que ocorrem em nós de maneira contingente com a história de nossas interações", então viver de uma forma ou de outra na linguagem, não é trivial. Nesse sentido, talvez possamos pensar a música com bebês como um tempo e espaço de viver e constituir repertórios sonoros, musicais, gestuais, de texturas, de cantos, de palavras, a partir de experiências estético/poéticas vividas ludicamente por cada bebê no coletivo.

O irrepetível e único da confluência vital entre experiência estética e experiência poética emergem dos fazeres transformativos do corpo, que promovem a propagação da sensualidade do sentir. Aqui não há modelo ou método a seguir, pois é projetando ações no 
mundo, na tomada de decisão de interagir em linguagem com outros, realizando uma experiência e sendo essa própria experiência, que emerge a abertura ao que nos torna simultâneos com os outros e com o mundo: movimentando-se, falando, desenhando, rindo, cantando, pintando, chorando, tocando. Nesse sentido, consideramos relevante não isolar a presença da música na creche das demais formas de estar em linguagem (fala, choro, silêncio, desenho, narrativa, movimento/dança), pois

\begin{abstract}
a comunicação implica tanto a palavra quanto os movimentos do corpo e a utilização pelos atores tanto do espaço quanto do tempo. Tratar o enraizamento físico da palavra pronunciada, ou seja, a série de signos corporais que as acompanham como 'comportamento não-verbal', seria tão natural quanto referir-se à noite como o 'nãodia'. Nada obstante, um julgamento de valor nisso se exprime: trata-se do desprezo da simbólica corporal, tida por subalterna em consequência de sua associação a uma simples e superficial glosa da palavra emitida, a qual seria preeminente na hierarquia do sentido. (LE BRETON, 2009, p. 41).
\end{abstract}

O autor permite compreender que a desvalorização educacional do corpo expressivo como raiz ou fonte primal de nosso estar-no-mundo favorece a fragmentação da linguagem em diferentes linguagens e legitima sua generalizada divisão em "verbal" e "não-verbal". Porém, antes de classificar ou analisar, abordar a experiência de instaurar e transfigurar sentidos na convivência - seja com a música, com a pintura, com a dança, com a poesia, com o desenho - é abarcar os modos como o corpo sensível aprende a plasmar relações no mundo com outros, ou seja, é experiência linguageira de abertura sensível ao outro, de si e do mundo.

\title{
3 EDUCAR O SENSÍVEL NA CONTEMPORANEIDADE
}

Abordar a música é também abordar a experiência sensível do tempo e do silêncio. Portanto, consideramos importante discutir na educação, em especial no âmbito da educação de bebês e crianças pequenas, a relevância da experiência com e do silêncio, ou seja, a relevância de garantir a existência de momentos de silêncio. Não apenas nos encontros com a música, mas em todos os âmbitos da educação e da vida torna-se importante garantir tempos mais lentos que permitam a percepção da emergência do silêncio. De um silêncio que excede a linguagem em seus poderes de significar muito mais do que é possível dizer e, portanto, não é fracasso e sim “o acabamento, a culminação da linguagem” (KOVADLOFF, 2003, p. 25). Como pensar a experiência de tal complexidade da linguagem na educação com bebês e crianças pequenas? E ainda, qual o compromisso do educador com as memórias das crianças? 
A complexidade das interrogações está no tempo da experiência ser um tempo de entrega diferente para cada adulto e cada criança, simultaneamente singular e plural. Larrosa (2002), ao conceber a experiência como aquilo que "nos passa" e não "o que se passa", ou essa "inversão de voltar-se sobre si mesma" (LAZZARIN, 2013, p. 409), destaca que essa experiência de nossa aderência às coisas é cada vez mais rara por vivermos tempos acelerados demais, por não termos mais tempo à nossa disposição.

Tudo o que se passa, passa demasiadamente depressa, cada vez mais depressa. E com isso se reduz o estímulo fugaz e instantâneo, imediatamente substituído por outro estímulo ou por outra excitação igualmente fugaz e efêmera. $\mathrm{O}$ acontecimento nos é dado na forma de choque, do estímulo, da sensação pura, na forma da vivência instantânea, pontual e fragmentada. A velocidade com que nos são dados os acontecimentos e a obsessão pela novidade, pelo novo, que caracteriza o mundo moderno, impedem a conexão significativa entre acontecimentos. Impedem também a memória, já que cada acontecimento é imediatamente substituído por outro que igualmente nos excita por um momento, mas sem deixar qualquer vestígio. $\mathrm{O}$ sujeito moderno não só está informado e opina, mas também é um consumidor voraz e insaciável de notícias, de novidades, um curioso impenitente, eternamente insatisfeito. Quer estar permanentemente excitado e já se tornou incapaz de silêncio. Ao sujeito do estímulo, da vivência pontual, tudo o atravessa, tudo o excita, tudo o agita, tudo o choca, mas nada lhe acontece. Por isso, a velocidade e o que ela provoca, a falta de silêncio e de memória, são também inimigas mortais da experiência. (LARROSA, 2002, p. 23, grifos nossos).

Os tempos lentos para a experiência estésica da escuta é algo raro, no dia a dia das crianças nas cidades. Vivemos em um mundo tecnoracional, no qual a imposição do excesso de ruídos, sons e imagens promovem uma simplificação do sensível pela aceleração de experiências sonoras, visuais, táteis, em praticamente todos os âmbitos do cotidiano dos adultos e das crianças. A falta generalizada de tempo, a vida acelerada pela proliferação de informações, o excesso de sons, ruídos e imagens impostas pelo mundo adulto promove diferenças nos modos dos adultos e dos bebês conviverem com outros. Para Maturana (1997, p. 168), "o que fazemos em nosso linguajar ${ }^{15}$ tem consequências em nossa dinâmica corporal, e o que acontece em nossa dinâmica corporal tem consequências em nosso linguajar”. Portanto, resistir à tendência da vida contemporânea, que ocorre em um contexto ruidoso e acelerado, implica investir no sonho de, quem sabe, contribuir para transformá-lo em longo prazo. Para Maturana (1999b), o que aprendemos tende a permanecer em nós porque a

\footnotetext{
${ }^{15}$ Neologismo que faz referência ao ato de estar na linguagem sem associar tal ato à fala, como aconteceria com a palavra falar. Maturana (1997, 1999a) utiliza o termo "linguajar" para enfatizar seu caráter de atividade, de comportamento e não de uma "faculdade" própria da espécie.
} 
educação é um processo contínuo que dura toda a vida, e que faz da comunidade onde vivemos um mundo espontaneamente conservador, ao qual o educar se refere. Isso não significa, é claro, que o mundo do educar não mude, mas sim que a educação, como sistema de formação da criança e do adulto, tem efeitos de longa duração que não mudam facilmente. (MATURANA, 1999b, p. 29).

Não significa a ilusão de transformar o que aí está posto como sociedade de consumo, mas sonhar com a possibilidade de minimizar a hegemonia de determinados valores que nos anestesiam porque nos habituam ao aceleramento dos sentidos. Trata-se de levar em conta a realidade em constante mudança para refletir possibilidades educacionais de oferecer um antídoto aos modos de viver nessa sociedade ruidosa e acelerada. Seria esse antídoto uma maior atenção para o detalhe, para a lentidão, para a estesis, para a educação do sensível?

Para enfatizar a aproximação entre a falta de silêncio e a falta de memória e a falta de experiência apontadas na leitura de Larrosa (2002), consideramos importante pensar com Merleau-Ponty (2011, p. 246) o papel do corpo na memória e, com ele, reafirmar que só podemos abarcá-la se compreendermos que a memória

\footnotetext{
não é a consciência constituinte do passado, mas um esforço para reabrir o tempo a partir das implicações do presente, e se o corpo, sendo nosso meio permanente de "tomar atitudes" e de fabricar-nos assim pseudopresentes, é o meio de nossa comunicação com o tempo, assim como com o espaço. (MERLEAU-PONTY, 2011, p. 246).
}

É a delicada e surpreendente exigência linguageira de ter de imprimir sentidos aos acontecimentos na simultaneidade que nos coloca a difícil tarefa de escolher e tomar decisões. É na existência, vivendo, que constituímos e imprimimos sentidos aos fenômenos pessoais e coletivos. Por isso, o corpo que a fenomenologia merleaupontiana elogia - o corpo próprio ${ }^{16}$ - não é um "eu quero" ou um "eu desejo" e sim um "eu posso" em sua comunicação com o tempo (agora) e com o espaço (aqui).

Assim, essa incapacidade de silêncio, essa falta de memória, essa eterna insatisfação que nos fala Larrosa (2002), aponta um anestesiamento nos modos de viver contemporâneo que reclama a necessidade de educar o corpo sensível em sua potência de agir no mundo. Para Duarte Jr. (2001), a desconsideração contemporânea pela educação do sensível pode ser abordada como a crise de certo modo de conhecer que expõe certo modo do corpo - seus cinco sentidos e sua capacidade interativa e comunicativa - se relacionar com o mundo. Para o autor, a estesia, o saber sensível, “consiste fundamentalmente num experienciar a beleza, já

${ }^{16}$ Cf. Merleau-Ponty (2011, pp. 192, 269, 315). 
que as coisas se nos revelam como prazerosas e surpreendentes, ainda que, às vezes, assustadoras ou terríveis" (DUARTE Jr.. 2001, p. 16).

Nessa perspectiva, considera importante contrapor ao atual entorpecimento ou "embrutecimento" do corpo, a evidência da experiência da beleza como componente fundamental do saber sensível, pois "nos anima a saber, a procurar, a querer desfrutar o desconhecido, em busca de seu sabor e de seu sentido para nossa existência" (DUARTE JR., 2001, p. 155). Porém, atualmente "conceito algum passou a ser mais repudiado do que este" pelo equívoco de relacioná-la estritamente com modelos de harmonia e pureza, a partir de padrões definidos pelas modas e imposições da indústria cultural, e assim promover o esquecimento educacional de que a experiência da beleza "emerge de raízes corporais de nosso estar-no-mundo, mostrando-se colada à inquietude e ao prazer de nossos sentidos aisthesis" (DUARTE JR., 2001, p. 154-155).

Para Meira e Pillotto (2010, p. 56), a importância do silêncio, de pausas nos contextos da vida, é "uma forma de potencializar os afetos sob diferentes investiduras, seja no contexto da escola ou em outros contextos e culturas dos quais fazemos parte". Para Kovadloff (2003, p. 76), fazer música ou escutá-la equivale, "profundamente, a guardar silêncio", ao "capturar o instante e o refletir sem se deter”, portanto para obter silêncio é necessário fazer música, pois "a música semeia o silêncio nos sons, transplanta o inefável ao campo acústico" (KOVADLOFF, 2003, p. 75).

Para Kovadloff (2003, p. 64), ouvimos o transcurso do silêncio sempre pela "primeira vez”, por ser da música simultaneamente nos oferecer o desconhecido e ao desconhecido, pois "no espírito de quem sabe ser seu ouvinte, é extrema a vibração dessa oferenda da qual se é, simultaneamente, matéria e destinatário. Ela adverte que o indizível se presta a ser ouvido mas não a ser decifrado". Nessa perspectiva, o silêncio "não constitui um conteúdo e sim uma singular tensão entre conteúdos" e sua apreensão musical equivale "à sua recriação. Eco de um eco, a música não designa o silêncio: o prolonga. Trata-se de uma atmosfera de virtualidade semântica que se esgota em sua condição de estrita promessa, sem ultrapassá-la jamais" (KOVADLOFF, 2003, p. 64). Para argumentar seu reconhecimento da música como um sinônimo de silêncio - "ao silêncio extremo como som musical", o autor afirma que

se o silêncio não é necessariamente ausência de som, e sim presença de um sentido que excede nossa compreensão, então a música pode ser expressão do silêncio. $\mathrm{O}$ que significa ouvir o silêncio senão escutar o que não chega a ser dito? A música remete, desta forma, não a uma diminuição de significação, e sim a uma plenitude 
que supera a aptidão compreensiva. Ela é, por si mesmo, configuração metafórica do silêncio. Sem transmitir-nos o que ele diz, nos diz, em troca, que alguma coisa ele quer nos transmitir. (KOVADLOFF, 2003, p. 75-76).

Porém, especialmente no contexto educacional, o silêncio concebido como uma modalidade do ser sonoro - pois "toda ausência é apenas o avesso de uma presença" (MERLEAU-PONTY, 2011, p. 488) -, não é valorizado. O que a cultura escolar espera é um silêncio silenciado, uma ocultação ou negação. Trata-se daquele que Kovadloff (2003, p. 24), ao abordar o silêncio poético como "silêncio da significação excedida", denomina por polarização de "silêncio da oclusão". Esse silêncio é assim nomeado por emergir de uma linguagem na qual a experiência do extraordinário é subjugada pela obviedade e se dissolve na rotina do não estranhamento, pois "na linguagem do hábito jaz - justamente silenciada uma dimensão de sentido do real que, como matriz, é decisiva para a compreensão do valor da existência".

Para Derdyk (2001, p. 81), "somos manifestação de estados anímicos de beleza, de horror, de prazer, de dor, de sentimentos de reciprocidade e animosidade, atitudes de entrega e defesa. Somos sim e somos não". Talvez, o que não ocorra com frequência no ambiente escolar seja justamente o favorecimento para esse trânsito lúdico entre o que somos e o que não somos, entre espaço "real" e espaço "existencial 17". Em contextos educativos, para Meira e Pillotto (2010), vigoram métodos de ensino que priorizam a explicação e a fragmentação do vivido, exigindo a paralisação do corpo e seus processos interativos com o mundo. Mas, como afirmam as autoras, o silêncio não significa "imobilidade corpórea", antes implica "atenção e espera, nas quais a vida escolhe o momento para entrar em cena, movimentar os agentes criadores que estão latentes naquilo que todos os humanos fazem" (MEIRA; PILLOTTO, 2010, p. 56). Assim, destacam a importância dos processos de aprender a interagir com o silêncio como resgate de energias sensíveis.

Diante da intensidade da presença de ruídos sonoros em todos os contextos contemporâneos, configurando uma soma que preenche cada vez mais espaços e tempos do cotidiano, compartilhamos com Meira e Pillotto (2010, p. 56) a relevância educacional de buscar "cenários, gestos, movimentos que agreguem vitalidade às nossas potencialidades infinitas" como modo de preencher nossa existência com pausas (silêncios) que contribuem

\footnotetext{
${ }^{17}$ Cf. Heller (2006, p. 170), existencial no sentido de $e k$-stase - que, literalmente, significa "dar um passo à frente ou para fora", ou seja, aparecer: um campo de presença, um campo temporal. Portanto, não necessariamente no sentido da corrente filosófica do existencialismo, mas no sentido heideggeriano de "leque de possibilidades aberto ao ser-ầ'.
} 
para instantes ou momentos de reflexão e de compreensão corporificados que reverberam na convivência.

Aqui, com Kovladoff (2003, p. 85), cabe explicitar o "árido território do ruído", o que provém do espaço - estancado no espaço - e jamais diz respeito ao tempo, para destacar que, à diferença do que ocorre na música, "no ruído os sons não denotam aptidão para a convivência. Fustigam-se uns a outros e dessa hostilidade sem trégua brota a dissonância, a sonoridade desencontrada". Saber do ruído como "domínio da desmesura rude e do fragmentário que se satisfazem abertamente em sua própria parcialidade" é compreender com Kovadloff (2003, p. 87) que isso importa saber, pois uma coisa é reconhecer que aspiramos à totalidade sem nunca a alcançarmos, por ser uma impossibilidade do humano, e outra bem diversa é satisfazer-se com a insuficiência, conviver com a parcialidade do "ruidoso propósito do entretenimento" (HOYUELOS, 2007, p. 26), convertendo o demérito em mérito e nele nos satisfazermos como se fosse aquilo que gostaríamos de fazer.

Para o poeta e ensaísta argentino Kovadloff (2003, p. 24), a relevância do silêncio que habita a linguagem poética está em constituir "um corte interpretativo no campo total do inteligível. Pode nomear algo de certo modo, somente com a condição de que silencie alguma coisa, também de certo modo". O autor, nessa perspectiva, acredita em uma trajetória poética que "vai do silêncio ao silêncio. De um silêncio a outro silêncio" (KOVADLOFF, 2003, p. 23). Esse silêncio extraído do poético resulta "de uma linguagem: aquela que reina onde a aglutinação disseminada pela obviedade extenuou o dom do estranhamento; linguagem que impera onde o sentimento do extraordinário cede subjugada e se dissolve na maré ascendente da rotina" (KOVADLOFF, 2003, p. 23-24). O que o autor sublinha como experiência poética promovida pelo silêncio que emerge da linguagem, Derdyk (2001, p. 19) destaca como um fazer que presentifica "a natureza móvel, imprecisa, potente, intempestiva e incisiva do ato criador”. Por isso, para Lino (2010, p. 85), nos encontros com as crianças,

\footnotetext{
a música não ignora o ruído, não idolatra a canção, nem um tipo específico de construção sonora, mas cria relações no risco e no excesso de experimentar a ludicidade do corpo e das paisagens sonoras do entorno. Sendo uma longa conversa entre $o$ som e $o$ silêncio, a música artesanalmente orquestrada pelas crianças expressa seus elementos constituintes, administrados pelas culturas infantis numa simultaneidade heterofônica. Nessa ação, a música como substantivo plural não prescreve, mas emerge na infância como brincadeira. (LINO, 2010, p. 84).
}

Nessa perspectiva, - tão estética quanto poética - da potência brincante das crianças com a linguagem, compartilhamos com Carlos Laredo, diretor da Companhia de Teatro "La 
Casa Incierta"18, companhia hispano-brasileira pioneira no campo das artes cênicas para a primeira infância, a preocupação com a constante tendência de oferecer experiências linguageiras - "produtos culturais" - aos bebês e crianças pequenas de forma simplificada. Porém, para Laredo (2003, p. 8), “o processo de secar as almas por inanição cultural é responsabilidade de todos. Crescemos exilados do sentir e do olhar interno profundo. Exilados de nós mesmos e, no final, afastados da natureza e da vida". Significa compreender que "sem poética a vida humana carece de inspiração e profundidade e, em último termo, carece de sentido. Sem estética, a vida humana carece de bem estar e alegria, e ao mais se vive no ruidoso propósito do entretenimento”. (HOYUELOS, 2007, p. 26).

O grande obstáculo educacional a enfrentar é a desconsideração pelas dimensões estética e poética nos encontros entre adultos e bebês em espaços coletivos. Muitas vezes, o pressuposto de que bebês e crianças pequenas não sabem a nossa língua, não entendem nossas palavras, não alcançam os sentidos inscritos nos gestos, nos sons e nos olhares que nos situam no coletivo, gera um extremo cuidado para "não machucar" sua sensibilidade e, então,

\begin{abstract}
as emoções são narradas ou falsificadas, mas nunca vividas e autênticas. Tantas vezes se submete a criança à redoma protetora do adulto que o conteúdo se recheia de consignas de condutas transmitidas através de "imperativos categóricos" repetidos. Sustenta-se na falta de rigor artístico com técnicas de teatro de participação, de animação, diversão ou ócio, cheio de caricaturas empobrecedoras do espírito humano, e de fórmulas didáticas transmitidas com o sentimento de superioridade próprio do adulto sobre a criança. (LAREDO, 2003, p.4)
\end{abstract}

Interrogamos com Laredo (2003) o caráter reducionista no encontro linguageiro entre adultos e bebês pela eliminação da intensidade das experiências estéticas e poéticas, geralmente pela compreensão de que não são capazes de viverem o encantamento dado pela complexidade da experiência tão sensível quanto inteligível da música, do teatro, da poesia, da dança, das artes plásticas. Porém, como diz Merleau-Ponty (1999a, 24), “a criança compreende muito além do que sabe dizer, responde muito além do que poderia definir, e, aliás, com o adulto, as coisas não se passam de modo diferente". Trata-se de compreender com Richter e Barbosa (2010, p. 87) que “o bebê é muito ágil e inventivo; é poderoso em sua capacidade básica de se auto-organizar, autogerir, auto-administrar, escolher e tomar decisões para empreender ações e alcançar êxito nos resultados". Desde o nascimento, "a vida é um constante criar-se e destruir-se, uma constante transformação do informe na forma, do sem-

\footnotetext{
${ }^{18}$ http://lacasaincierta.com/
} 
sentido no sentido, do que carece de valor em algo valioso, do jogo do mundo, do jogo da criança, do jogo do artista" (LAREDO, 2003, p. 5). A vida é complexa em sua incompletude e finitude. E os bebês nascem na condição humana de enfrentá-la. Para Charlot (2000), nascer é

\begin{abstract}
penetrar nessa condição humana. Entrar em uma história, a história singular de um sujeito inscrita na história maior da espécie humana. Entrar em um conjunto de relações e interações com outros (...) significa ver-se submetido à obrigação de aprender (...). Nascer, aprender, é entrar em um conjunto de relações e processos que constituem um sistema de sentido, onde se diz quem eu sou, quem é o mundo, quem são os outros. Esse sistema se elabora no próprio movimento através do qual eu me construo e sou construído pelos outros, esse movimento longo, complexo, nunca completamente acabado, que é chamado educação. (CHARLOT, 2000, p. 53).
\end{abstract}

Afirmar a educação como movimento inacabado - sempre por aprender - supõe compreender, com Charlot (2000, p. 54), a educação como movimento auto-organizativo "de produção de si por si mesmo" a qual "só é possível pela mediação do outro e com sua ajuda". Cada um que fala ao outro, faz o outro sentir e pensar, provoca o outro a tornar-se aquilo que é, e que nunca seria sozinho. Na concepção de Merleau-Ponty, a linguagem desempenha papel fundamental na percepção do outro ao promover a experiência do diálogo, isto é, a experiência da intercorporeidade, "como existência originária do eu e do outro" (CHAUÍ, 2002, P. 147).

\begin{abstract}
Na experiência do diálogo, constitui-se um terreno comum entre outrem e mim, meu pensamento e o seu formam um só tecido, meus ditos e aqueles do interlocutor são reclamados pelo estado da discussão, eles se inserem em uma operação comum da qual nenhum de nós é o criador. Existe ali um ser a dois, e agora outrem não é mais para mim um simples comportamento em meu campo transcendental, aliás nem eu no seu, nós somos, um para o outro, colaboradores em uma reciprocidade perfeita, nossas perspectivas escorregam uma na outra, nós coexistimos através de um mesmo mundo. (MERLEAU-PONTY, 2011, p. 474).
\end{abstract}

Aqui, podemos compartilhar com Maturana (1999a, p. 29), a concepção de que educar se constitui no processo de conviver conversando com o outro, de viver na linguagem em "distintas redes de coordenações de coordenações consensuais de ações e emoções" (MATURANA, 2004, p. 31). Tal concepção de linguagem permite ao biólogo apontar que "todo o viver humano consiste na convivência em conversações e redes de conversações" e afirmar que "o que nos constitui como seres humanos é nossa existência no conversar" (MATURANA, 2004, p. 31).

O instigante para nós é também podermos conversar através do silêncio e da música e assim ampliarmos possibilidades singulares e coletivas de produção de significados na 
convivência entre adultos e bebês. Assim, resistimos à crença generalizada na incapacidade dos bebês interagirem e realizarem escolhas porque os priva de viver o fabuloso dado pela intensidade do encantamento pelo mundo, negando o direito inalienável de compartilharem experiências sensíveis como modo de complexificar processos de aprender a interagir com a pluralidade linguageira do humano. A música, desde a infância, emerge como presença e possibilidade de criação poética, de experiência estética, de invenção linguageira de sentidos que significam a co-existência.

O importante aqui é considerar com Duarte Jr. (2001), a educação do sensível como ampliação de outros modos de significar que não apenas o conceitual, ou seja, pela consideração educacional tanto do saber sensível quanto do conhecimento intelectivo já que privilegiar o sensível em detrimento do inteligível, seria reforçar a tendência esquizóide de nossa civilização moderna. $\mathrm{O}$ autor complementa reivindicando aos educadores sustentarem suas reflexões "em bases amplas, fundadas na percepção das conexões existentes entre os conhecimentos, os saberes, as expressões culturais e as ações cotidianas de todos nós" (DUARTE JR., 2001, p. 216).

Tal compreensão exige uma tarefa de revisão, não apenas no campo da educação musical, mas fundamentalmente da relação e das interações com a linguagem, com a cultura, com o sabor do mundo no cotidiano da educação infantil. Para Heller (2006, p. 59), desconsiderar a totalidade que envolve som e gesto, gesto e linguagem, corpo e expressão, implica tomá-los como partes que se somam numa relação de causa e efeito e "é exatamente nesse ponto que falham as várias 'metodologias' de ensino musical: ao insistir numa atitude mecanicista onde um determinado efeito é obtido através de determinado recurso".

Como contraponto a essa tendência, Lino (2008) traz importante contribuição ao afirmar que para as crianças pequenas "fazer música é brincar”, sendo "o barulhar a música das culturas da infância". Em sua pesquisa no maternal, mostrou que "todas as crianças produziam insistentemente barulhadas, vivendo o descontínuo como presença da natureza sonora ao expor uma miríade de explorações com a música como experimentação, jogos de escuta ou narrativas sonoras" (LINO, 2008, p. 8). A relevância do estudo está em permitir outro olhar tanto para a música das culturas infantis quanto para a ação de brincar, frequentemente tidas na cultura escolar como mera recreação, passatempo ou descarga de emoções, ao constatar em sua escuta sensível que 
as crianças deram estado de existência às sonoridades do mundo, expressando poeticamente a sua música, isto é, barulhando. Nesse momento, escutei a avassaladora complexidade e pluralidade revelada nas múltiplas e instigantes maneiras de brincar com sons dispostas especialmente nos tempos livres das crianças através de seus distintos jogos de barulhar. (LINO, 2010, p. 84).

Para Lino (2010, p. 83), ao fazer música brincando, as crianças são parte da experiência sonora que criam, e assim, constroem experiências e conexões significativas para si, pois "suspendem o automatismo das ações para entrar em relação com o som, matériaprima que provoca movimento apreendido pelo ouvido". Essa experiência sonora requer

\footnotetext{
interrupção, cultiva a escuta, mobiliza o corpo. Nessa ação, as crianças vivem as resistências das materialidades sonoras impostas ou expostas cotidianamente. Sendo do terreno da singularidade, tal experiência sonora produz diferença, heterogeneidade e pluralidade, tendo sempre uma dimensão de incerteza que, segundo Merleau-Ponty (1999), lhe possibilita a abertura ao desconhecido, para aquilo que ainda não somos. (LINO, 2010, p. 83).
}

A preocupação educacional que subjaz na obra de Lino (2008; 2010), assim como na de Heller (2006), a qual interessa nesse estudo, não é fazer uma crítica à educação musical, mas problematizar a experiência de educação musical. Não necessariamente a experiência do adulto educador, mas do fazer música, experiência por excelência da educação musical. Ambos os autores não interrogam o que a criança faz, mas como ela vivencia o que ela faz (HELLER, 2006). Portanto, os modos como o corpo sensível explora, experimenta, expressa e faz coisas no mundo, desde o nascimento, promove diferenças nos processos de aprender os ritmos que tecem as interações no coletivo.

Nesse sentido, interpretar a escuta de como ocorrem os primeiros interesses - ou primeiras sensações - pelas sonoridades e quais os indícios de uma interação linguageira que nos oferecem, implica a intenção de apresentar (viver com os) aos bebês e com eles viver, nos encontros semanais na creche, um repertório/memória sonoro/corporal/musical que valorize os tempos e os silêncios como ponto de partida das experiências estéticas e poéticas entre eles e os adultos. Exige abertura para o imprevisto e para o improviso por parte do adulto educador, sendo importante a presença da confiança e do encantamento ao viver junto o que para o outro ainda é novo.

\section{AESTHETIC / POETICAL ENCOUNTERS BETWEEN MUSIC AND BABIES IN NURSERY SCHOOL}




\begin{abstract}
This essay approaches the intimacy between the aesthetic and poetic dimensions of language in the context of nursery school and proposes a phenomenological listening of encounters between adults and babies through the experience of music as a playful action of the expressive body in the world. Considering that without aesthetics life lacks flavor and without poetics it lacks sense, the article focuses on the merleaupontian understanding of the sensitive body as the primary source of significance to assert the inseparability between sensitive and intelligible in the action of learning to co-exist. The educational intention is to claim another rationality to stand up to the simplifying trend in encounters between adults and babies with the plurality of ways of interacting in language. Thus, thinking the aesthetic and poetic event in the sense of poiesis and aisthesis terms - the link between sound and silence with life taken as its reflexive starting point - not what the baby does but how he experiences what he does in the musical encounters in nursery school. This study allows us to assert the vital and playful power of the expressive body feeling itself and the world in the plurality of ways of being in language that empowers everyday life through acting, producing, creating, doing.
\end{abstract}

Keywords: Babies' Education; Language; Music; Aesthetics; Poetics

\title{
ENCUENTROS ESTÉTICOS/POÉTICOS ENTRE MÚSICA Y BEBÉS EN LA GUARDERÍA INFANTIL
}

\section{Resumen}

El ensayo trata la intimidad entre las dimensiones estética y poética del lenguaje en el contexto de la guardería infantil, para proponer una escucha fenomenológica de los encuentros entre adultos y bebés con la experiencia de la música como acción lúdica del cuerpo expresivo en el mundo. Al considerar que sin estética, la vida carece de sabor de sentido, parte de la comprensión merleau-pontiana del cuerpo sensible como fuente primera de significación para afirmar la inseparabilidad entre sensible e intangible en la acción de aprender a coexistir. La intención educacional es reclamar otra racionalidad para resistir a la 
tendencia simplificadora en los encuentros entre adultos y bebés con la pluralidad en los modos de interactuar en lenguaje. Por lo tanto, piensa el acontecimiento estético y poético en el sentido de los términos aisthesis y poiésis - del vínculo de la sonoridad y del silencio con la vida, tomando como punto de partida reflexivo no lo que el bebé hace, sino como la experiencia lo hace en los encuentros musicales en la guardería. El estudio permite afirmar la potencia vital y lúdica del cuerpo expresivo, sentir a sí mismo y al mundo en la pluralidad de los modos de estar en lenguaje que dinamizan la vida cotidiana del actuar, producir, crear, hacer.

Palabras clave: Educación de Bebés; Lenguaje; Música; Estética; Poética

\section{REFERÊNCIAS}

ARENDT, Hannah. A condição humana. Posfácio de Celso Lafer. Rio de Janeiro: ForenseUniversitária, 2004.

BOURSCHEID, Clarice de Campos. Escuta estética/poética na creche: encontros musicais com bebês e crianças pequenas. 2014. 228f. Dissertação (Mestrado em Educação) - UNISC, Santa Cruz do Sul.

CABANELLAS, Isabel. Un acercamiento a los ritmos infantiles. In: CABANELLAS, I. et al. Ritmos infantiles: tejidos de un paisaje interior. Barcelona: Octaedro, 2007.

CABANELlAS, I.; ESLAVA, J. J.; POLONIO, R. El tiempo en la construcción de la realidad. In: CABANELLAS, I. et al. Ritmos infantiles: tejidos de un paisaje interior. Barcelona: Octaedro, 2007.

CHARLOT, Bernard. Da relação com o saber: elementos para uma teoria. Porto Alegre: Artmed, 2000.

CHAUÍ, Marilena. Experiência do pensamento: ensaios sobre a obra de Merleau-Ponty. São Paulo: Martins Fontes, 2002.

DERDYK, Edith. Linha de horizonte: por uma poética do ato criador. São Paulo: Escuta, 2001.

DUARTE JR., João-Francisco. O sentido dos sentidos: a educação (do) sensível. Curitiba: Criar, 2001.

ESLAVA, Juan José. La escuela: desarrollo de los tiempos de la infancia. In: CABANELLAS, I. et al. Ritmos infantiles: tejidos de un paisaje interior. Barcelona: Octaedro, 2007. 
FERRÃO, A. M.; RODRIGUES, P. F. Sementes de música para bebés e crianças. Portugal: Caminho, 2008.

HELLER, Alberto Andrés. Fenomenologia da expressão musical. Florianópolis: Letras Contemporâneas, 2006.

Disponível

Motricidade e expressão musical. Ponto de vista, Florianópolis: UFSC, n. 9, 2007. https://periodicos.ufsc.br/index .php/pontodevista/article/viewFile/20424/18658. Acesso 20 nov. 2013.

HOYUELOS, Alfredo. Vivir los tiempos emocionados de la infancia. Prólogo. In: CABANELLAS, I. et al. Ritmos infantiles: tejidos de un paisaje interior. Barcelona: Octaedro, 2007.

KOVADLOFF, Santiago. O silêncio primordial: ensaios. Rio de Janeiro: José Olympio, 2003.

LAREDO, Carlos. O olhar exilado das crianças. Boletín de la Institución Libre de Enseñanza. Madrid/Espanha: Fundación Dialnet, Universidad de la Rioja, n. 49-50, Junho, 2003. Disponível em: http://celeirodasantas.blogspot.com.br/2009/05/o-olhar-exilado-dascriancas.html. Acesso em 18 set. 2013.

LAROSSA, Jorge. Notas sobre a experiência e o saber de experiência. Revista Brasileira Educação [online], Rio de Janeiro, n. 19, jan./abr., 2002. Disponível em: http://www.anped.org.br/rbe/rbedigital/rbde19/rbde19_04_jorge_larrosa_bondia.pdf. Acesso em: 13 out. 2012.

LAZZARIN, Luís Fernando. Educação da sensibilidade estética e multidimensionalidade: sentidos da experiência da música nas "fillosofias" da educação musical. In: SIMPÓSIO DE ESTÉTICA E FILOSOFIA DA MÚSICA - SEFiM/UFRGS, 2013, Porto Alegre. Anais... Porto Alegre: UFRGS, 17 a 18 out. 2013, v. 1, n.1, p. 402-415, 2013.

LE BRETON, David. As paixões ordinárias: antropologia das emoções. Petrópolis, RJ: Vozes, 2009.

LINO, Dulcimarta Lemos. Barulhar: a música das culturas infantis. Revista da ABEM, Porto Alegre: ABEM, n. 24, set. 2010. Disponível em: http://www.abemeducacaomusical.org.br/Masters/revista24/revista24_artigo9.pdf. Acesso em: 20 set. 2013.

Barulhar: a escuta sensível da música nas culturas da infância. 2008. 392 f. Tese (Programa de Pós-Graduação em Educação - Doutorado em Educação) - UFRGS, Porto Alegre, 2008.

MATURANA, Humberto. Transformación en la convivencia. Santiago: Dolmen, 1999a. 

1999b.

Emoções e linguagem na educação e na política. Belo Horizonte: Editora da UFMG,

Conversações matrísticas e patriarcais. In: MATURANA, H. R.; VERDENZOLLER, G. Brincar e amar: fundamentos esquecidos do humano. São Paulo: Palas Athenas, 2004.

MEIRA, M.; PILLOTTO, S. Arte, afeto, educação: a sensibilidade na ação pedagógica. Porto Alegre: Mediação, 2010.

MERLEAU-PONTY, Maurice. Fenomenologia da percepção. Martins Fontes: São Paulo, 2011.

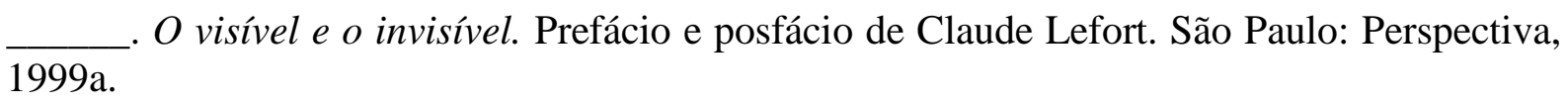

MESCHONNIC, Henri. Célébration de la póesie. Paris: Éditions Verdier, 2001.

PAZ, Octávio. O arco e a lira. São Paulo: Cosac Naify, 2012.

RICHTER, Sandra R. S. Artesanato das linguagens na infância. In: HILLESHEIM, B.; GUSTSACK, F.; VIEGAS, M. F. (Orgs.). Pesquisa, políticas e formação de professores: distintos olhares. Santa Cruz do Sul: EDUNISC, 2011.

Manchando e narrando: o prazer visual de jogar com cores. In: CUNHA, Susana R. V. da C. (Org.). Cor, som e movimento: a expressão plástica, musical e dramática no cotidiano da criança. Mediação: Porto Alegre, 2009.

; BARBOSA, Maria Carmen S. Os bebês interrogam o currículo: as múltiplas linguagens na creche. Educação, Santa Maria: UFSM, v. 35, n. 1, jan./abr .2010. Disponível em: file:///C:/Users/sandra/Downloads/1605-5618-1-PB\%20(1).pdf. Acesso em: 15 ago. 2013.

; FRONCKOWIAK, Ângela C. A tensão lúdica entre brincar e aprender na infância. Pátio Educação Infantil Ano IX, Porto Alegre, Grupo A, n. 27, abr./jun. 2011. Disponível em: http://www.grupoa.com.br/revista-patio/Edicoes_Anteriores.aspx. Acesso em: 01 abr. 2013.

; MURILLO, M.; BERLE, S. Aprendendo com o mundo: ação autônoma e jogo heurístico na educação de bebês. In: IX ANPED SUL, 2012,Caxias do Sul, 2012. Anais... Caxias do Sul: UCS, 2012. p.1-12. Disponível em: http://www.ucs.br/etc/conferencias/index.php/anpedsul/9anpedsul/paper/viewFile/3220/30. Acesso em: 05 fev. 2013.

RICOEUR, Paul. Paul Ricoeur: o único e o singular. São Paulo: Editora UNIESP; Belém, PA: Editora da Universidade Estadual do Pará, 2002. Íntegra das entrevistas Nomes de Deuses de Edmond Blattchen. 
RICHTER. S.; BOURSCHEID, C. C.

TARDOS, A.; SZANTO, A. O que é autonomia na primeira infância? In: FALK, Judite (Org.). Educar os três primeiros anos: a experiência de Lóczy. Araraquara: JM, 2004.

VALÈRY, Paul. Primeira aula do curso de poética. In: . Variedades. São Paulo: Iluminuras, 1999.

VECCHI, Vea. Estética e aprendizagem. Prólogo. In: HOYUELOS, Alfredo. La estética en el pensamiento y obra pedagógica de Loris Malaguzzi. Barcelona: Ediciones Octaedro; Asociación de Mestres Rosa Sensat, 2006.

Data de recebimento: 25/02/2014

Data de aceite: $17 / 03 / 2014$ 